\title{
Sustainable polymer-based Phase Change Materials for energy efficiency in buildings and their application in aerial lime mortars
}

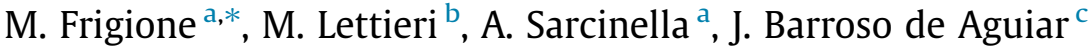 \\ a Innovation Engineering Department, University of Salento, Italy \\ ${ }^{\mathrm{b}}$ Institute of Archaeological Heritage, Monuments and Sites, CNR-IBAM, Italy

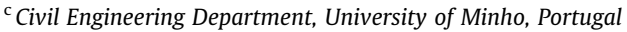

\section{H I G H L I G H T S}

- Sustainable low toxic form-stable PEG/waste Lecce stone PCM were produced.

- The Thermal Energy Storage capacity of produced PCMs was investigated.

- Different analyses confirmed that LS/PEG PCMs possess appropriate LHTES properties.

- The produced PCM were incorporated in aerial lime-based mortars.

\section{A R T I C L E I N F O}

Article history:

Received 25 February 2019

Received in revised form 21 September

2019

Accepted 3 October 2019

\section{Keywords:}

Aerial lime-based mortars

Form-stable method

Latent-heat

Mechanical properties

Phase Change Material (PCM)

Sustainable materials for buildings

\begin{abstract}
A B S T R A C T
An experimental study aimed at investigating the possibility to produce a Phase Change Material (PCM) for mortars by incorporating through the "form-stable method" a thermoplastic low-melting polymer (PEG 1000) into a porous inert substrate (i.e., Lecce Stone), obtained as residue from processing stone, is reported. The viscosity of pure PEG at different temperatures was first assessed to identify an appropriate processing temperature to introduce fluid PEG into the pores of the stone. A complete (chemical, thermal and morphological) characterization was performed on the developed PCM composites, varying the impregnation times. Aerial lime-based mortars were produced with the addition of the selected experimental PCM composite, taking as comparison the mortar containing only the stone as inert aggregate. On the different mortars, mechanical tests were performed in both compression and bending mode and the thermal conductivity was measured.
\end{abstract}

(c) 2019 Elsevier Ltd. All rights reserved.

\section{Introduction}

The increasing concern about climate change represents a stimulus pushing the research to identify new and alternative ways to decrease the world energy consumption. The awareness that fossil fuel is a limited and non-renewable resource is widespread; in addition, oil derivatives produce serious pollution and contribute to create heavy environmental impact. Starting from these considerations, one of the main objectives of international policy is to incentive the research aimed at developing new renewable energy solutions [1].

\footnotetext{
* Corresponding author.

E-mail addresses: mariaenrica.frigione@unisalento.it (M. Frigione), mariateresa. lettieri@cnr.it (M. Lettieri), antonella.sarcinella@unisalento.it (A. Sarcinella), aguiar@civil.uminho.pt (J. Barroso de Aguiar).
}

According to the International Energy Agency (IEA), the building sector is one of the largest consumers of energy since the indoor thermal comfort became an unavoidable need for the occupants. In recent years, among the proposed solutions and technologies, able to limit the energy consumption of buildings, Thermal Energy Storage (TES) is considered among the best approaches to improve the indoor energy efficiency [2]. Referring to this technology, a Phase Change Material (PCM) can be selected as the thermal storage medium [3-10].

The operating principle of a PCM consists in its solid - liquid transition, according to the external (environment) temperature. During daytime, when the external temperature is high, the PCM melts, storing the enthalpy involved in the melting process. The PCM material is, then, able to release the previously stored energy when the external temperature decreases, coming back to the solid state [11]. Thus, the addition of PCMs in construction materials can 
be a possible and an efficient way to reduce energetic consumption and $\mathrm{CO}_{2}$ emissions in the environment.

Different PCMs have been investigated in the very last years for this purpose. The main objective of this technology is to obtain a final material able to improve the thermal efficiency of the buildings, increasing the thermal comfort conditions of occupants, thus reducing energy consumption for heating and cooling $[12,13]$.

There are different methods to incorporate a PCM in building materials: direct incorporation, direct immersion, (micro or macro -) encapsulation, shape - stabilization, form stable method.

Direct incorporation is the simplest and most economical method since the PCM is directly mixed with the construction material $[2,13]$. In the case of the immersion method, the porous building materials are immersed in the melted PCM: the porous media, thus, absorbs the phase change product by capillarity [14], and this latter is retained directly in the building.

The encapsulation method is the most common technology. Two PCM encapsulation methods are commonly reported, i.e. micro - encapsulation and macro - encapsulation [15-19]. In micro - encapsulation, small PCM particles, ranging from $0.1 \mu \mathrm{m}$ to $1 \mathrm{~mm}$, are enclosed in a thin solid shell usually made from natural or synthetic polymers [20]. In macro - encapsulation technology, bigger capsules (such as tubes, spheres and panels) are able to contain a significant amount of PCM [21,22].

A different PCM encapsulating method has been recently developed, proving to be the most promising technique, although very complex in the implementation [23]. In this method, known as "shape - stabilization", the PCM and the support material (in general a polymer) are melted and mixed together at high temperatures. The support polymeric material is, then, cooled down, below its glass transition temperature, until it becomes solid, while the PCM is still in liquid state, well bounded in the free space of the support network $[24,25]$.

Finally, form-stable PCMs can also be prepared, where, again, a support porous matrix contains the PCM. Form - stable composite PCMs received a great attention very recently, they can be obtained by simple immersion of the matrix in the liquid PCM, possible aided by vacuum [21]. It is a very easy and cheap method, retains an optimum percentage of PCM, with no leakage even when the temperature is above the melting point of PCM $[25,26]$.

In this paper, the first part of a wide research, aimed at producing a form - stable PCM composite, based on sustainable materials, to be included in mortars composed by different binders, is reported. The objective of the research program is to prove the thermal efficiency of the obtained sustainable PCM to manufacture mortars based on lime, gypsum and cement, still displaying suitable mechanical properties for the selected (indoor/outdoor) applications. In the present paper, the procedures employed to realize a form - stable PCM composite, and the complete characterization of this latter system, are reported. Furthermore, the results obtained in the study of aerial lime-based mortars containing the obtained PCM, are also illustrated.

The composite system was produced employing as support small pieces of Lecce Stone (LS) available as a waste product, in order to maintain low, the costs and to respect eco-sustainable principles. The whole production of stone blocks employed in constructions, i.e. from extraction to finished products, generates a huge amount of waste material, in solid or powder form [27]. The presence of this waste product poses an environmental issue due to its non-biodegradable nature and to the lack of landfills large enough to dispose the waste stones. In these years, therefore, efforts have been made to identify original and innovative ways to reuse, and at the same time to exploit, this natural material [28].
The use of waste stone as support for a PCM able to improve the thermal efficiency of the buildings, and to reduce the consumption of petroleum-derived energy, would represent a double advantage for the environment.

Low toxic, low flammable PEG (Poly(ethylene glycol)) was selected as PCM. This product has been widely applied in conservation treatments of degraded (i.e., waterlogged or deteriorated by insect attack) wood, being able to replace the existing water inside the wood upon a gentle warming, and maintain long-term stability of both the material and the wooden structure [29]. Due to the availability of PEGs of different molecular weights, and thus different melting temperature range [30], a grade of PEG possessing an appropriate melting point with reference to the operating conditions for which is intended, was selected.

The favorable properties of PEG (suitable phase change temperatures and large phase change enthalpy, elevated long-term thermal/chemical stability, low toxicity and resistance to corrosion, limited volume change during solid-liquid phase change), its readiness to be incorporated into porous inert substrates and the possibility to select the more appropriate grade for the specific application, have suggested the use of PEG to manufacture efficient PCM systems [31,32]. To the best of our knowledge, this is the first time that this polymer has been employed to produce form - stable PCM composites by its impregnation in stone flakes obtained as by-products of the processing of a local (Lecce) stone. The further advantage and the sustainability of this choice, therefore, lie in the possibility of using residues of a low-added-value process in conjunction with a thermally efficient, cheap and low toxic PCM, employing an easy, effective and low-cost impregnation method.

The PCM form-stable systems were, then, used as aggregate in the production of aerial lime-based mortar formulations.

The main aims of the research described in this paper were the production and the optimization of the composition of a new sustainable PCM, i.e. LS/PEG composite, obtained through vacuum impregnation. A complete (i.e., chemical, physical and thermal) characterization of LS/PEG composite was performed. Results of the mechanical tests performed on aerial lime-based mortars containing LS/PEG composite as aggregates, are reported. In particular, the influence of the PCM inclusion on some properties of the mortars, i.e. workability, compressive and flexural strengths, was analyzed.

\section{Materials and methods}

\subsection{Materials}

Lecce Stone (LS) was selected as support matrix to produce the composite PCM. Lecce stone is a biocalcarenite, used from centuries in historical buildings in the Southeastern Italy (Salento region), especially during the Baroque period. This material is mainly composed of $\mathrm{CaCO}_{3}(92-95 \%$ wt.) and, in a smaller percentage, of grains of glauconite, quartz, feldspars, muscovite, phosphates and clay minerals. LS is very suitable as a porous support to prepare PCM composites (especially using the form-stable method) because of its high open porosity and porosimetric features [33].

The LS used in this work was stone cutting waste from a quarry located near Lecce (Italy). The stone material was supplied in form of flakes (as shown in Fig. 1a); it was ground by a mill and, then, sieved to obtain small granules (illustrated in Fig. 1b), having a granulometry ranging between 1.6 and $2.0 \mathrm{~mm}$ [34].

Poly(ethylene glycol) (trade name PEG 1000) was selected as the true Phase Change Material. It was supplied from Sigma - Aldrich company (Germany) in solid form, as shown in Fig. 1c. The selection of PEG 1000 was driven by its favorable properties, such as non-toxicity, low environmental impact, low flammability; furthermore, it is relatively inexpensive and exhibits a melting temperature in the range $37^{\circ}-40^{\circ} \mathrm{C}$. According to the literature, in fact, an efficient PCM must display a transition from solid to liquid state near the human comfort temperatures (i.e., around $22^{\circ}-26^{\circ} \mathrm{C}$ ) $[14,35]$. However, in the Mediterranean regions, the external temperature can reach, or surpass, even $40^{\circ} \mathrm{C}$. This observation justified the selection of a PCM with phase transition in a slightly higher temperature range, if 


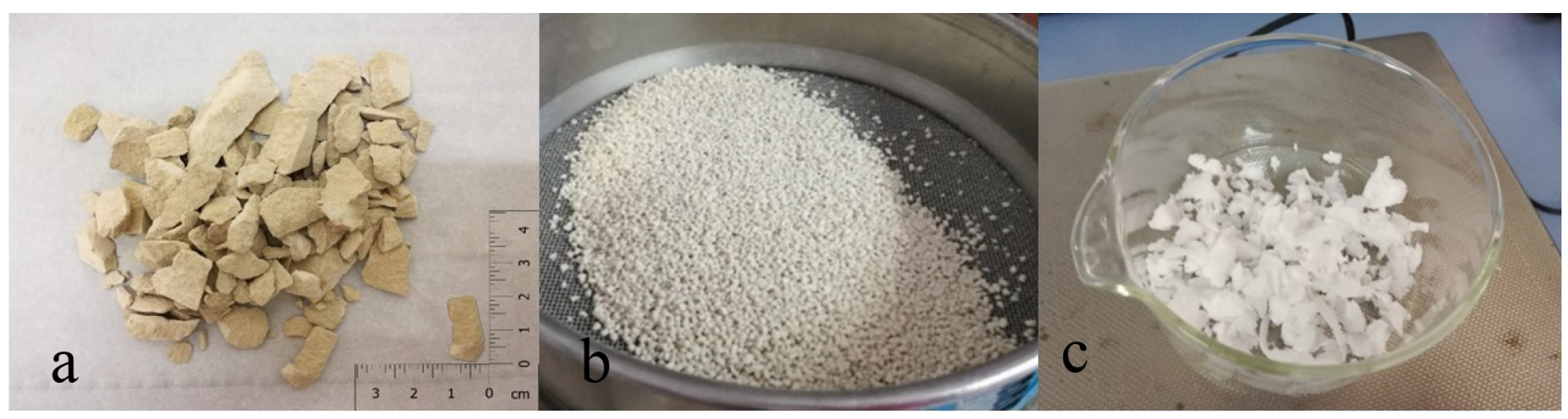

Fig. 1. (a) Flakes of Lecce Stone from the quarry; (b) ground and sieved Lecce Stone; (c) PEG 1000 in solid form.

intended as an energy efficiency measure to be employed in buildings located in the Mediterranean area. The density of PEG 1000, according to the technical data sheet, is $1.2 \mathrm{~g} / \mathrm{cm}^{3}$ (at $20^{\circ} \mathrm{C}$ ).

\subsection{Preparation of $L S / P E G$ composite}

The PEG Phase Change Material was incorporated in the stone granules using the form - stable principle, through the vacuum impregnation method. This technology was selected due to its low manufacture costs; in addition, an easily accessible laboratory equipment, showed in Fig. 2, is required.

First, a fixed amount of LS flakes was placed in a flask connected to a vacuum pump (at a vacuum pressure of $0.1 \mathrm{MPa}$ ). In this way, air, and possibly moisture, were removed from the stone; this procedure was carried out for $30 \mathrm{~min}$. The solid PEG was first heated in oven at $80^{\circ} \mathrm{C}$, in order to lead it in the fluid (melt) state. It was, then, added to the LS pieces in the flask, where a magnetic stir bar was also contained. The flask was placed on a magnetic stirrer, maintained at $60{ }^{\circ} \mathrm{C}$, for different processing times (from 10 to $60 \mathrm{~min}$ ). This processing temperature was selected on the basis of the results of calorimetric experiments and rheological tests performed on pure PEG at different temperatures, as will be described in the paragraph 3.1. Then, air was allowed to enter in the flask to force the liquid PCM to penetrate into the pores of LS. Table 1 reports the composition and process times employed to prepare the different LS/PEG systems.

No substantial differences were visually detected on LS granules impregnated with PEG employing different impregnation times. In Fig. 3, the LS granules impregnated with PEG are shown.

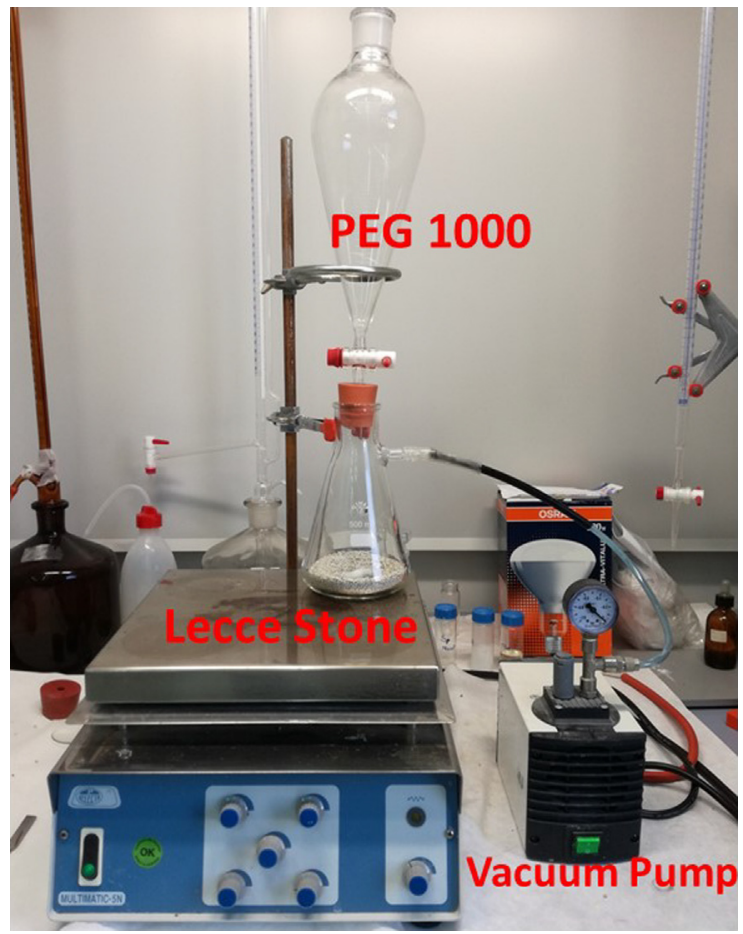

Fig. 2. Vacuum impregnation equipment employed to prepare the LS/PEG composite.
Table 1

Details of composition and processing times of the PCM-stone composites.

\begin{tabular}{lllll}
\hline Sample & LS $(\mathrm{g})$ & PEG $1000(\mathrm{~g})$ & $\begin{array}{l}\text { Vacuum } \\
\text { Time }(\mathrm{min})\end{array}$ & $\begin{array}{l}\text { Impregnation } \\
\text { Time }(\mathrm{min})\end{array}$ \\
\hline LS/PEG-10 & 50.0 & 10.0 & 30 & 10 \\
LS/PEG-30 & 50.0 & 10.0 & 30 & 30 \\
LS/PEG-60 & 50.0 & 10.0 & 30 & 60 \\
\hline
\end{tabular}

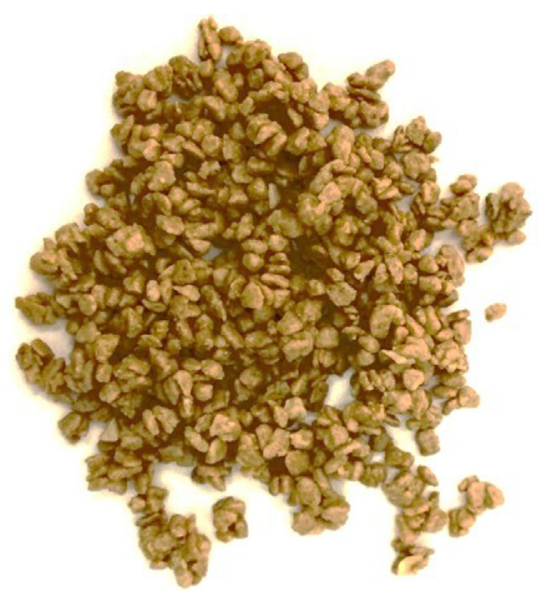

Fig. 3. Granules of Lecce stone impregnated with PEG.

\subsection{Production of aerial lime mortars}

The final purpose of the whole project was the identification of different compositions of mortars, containing the PCM composite and based on different binders, and the evaluation of their thermal properties as a function of the PCM content. Since it could be expected a certain reduction in mechanical properties of the mortars containing the PCM composite, the study proposed to identify for each kind of mortar the appropriate composition in order to obtain a good thermal efficiency, still maintaining appropriate mechanical properties for the typical applications suggested for the specific mortar.

The first step, therefore, consisted in the development of aerial lime-based mortar formulations containing PCM, in particular LS/PEG-60, with appropriate workability in the fresh state and adequate mechanical properties. The longest process time, i.e. $60 \mathrm{~min}$, was selected to produce the mortars containing LS/PEG composite, since this process parameter allowed to achieve the best impregnation of PEG in the LS (as it will be illustrated in "Results and Discussion" section). In order to assess the effects of the PCM inclusion in a mortar, both in its fresh and hardened state, different mortar formulations were produced adding LS/PEG composite as fine aggregates and aerial lime, supplied by a Portuguese company (i.e., Lhoist), as a binder. The aerial lime had a purity of $90 \%$ and a density of $2450 \mathrm{~kg} / \mathrm{m}^{3}$. For comparison purposes, similar formulations, including Lecce Stone as aggregates in the same composition, were prepared. In some of the mortar formulations, a superplasticizer (SP) was added in order to decrease the amount of water to be used for the mixing. The employed superplasticizer was a polyacrylate (MasterGlenium SKY 627), supplied by BASF, with a density of $1050 \mathrm{~kg} / \mathrm{m}^{3}$. The compositions of the produced 
Table 2

Mortar compositions (reported as $\mathrm{kg} / \mathrm{m}^{3}$ of produced mortar).

\begin{tabular}{|c|c|c|c|c|c|c|}
\hline System & Content of Binder & Aggregates & SP & Water & Water saturation & Water/Binder \\
\hline AL_L $L_{500}$ & 500 & 1500 & 0 & 289 & 378 & 0.60 \\
\hline AL_LS/PEG 500 & 500 & $\begin{array}{l}1500 \\
(P E G \text { component }=345)\end{array}$ & 0 & 395 & 0 & 0.80 \\
\hline $\mathrm{AL} \_L S_{500 \_S P}$ & 500 & 1232 & 15 & 225 & 414 & 0.45 \\
\hline AL_LS $800 \_S P$ & 800 & 175 & 15 & 600 & 44 & 0.75 \\
\hline AL_LS/PEG $800 \_S P$ & 800 & $\begin{array}{l}220 \\
(\text { PEG component }=51)\end{array}$ & 15 & 600 & 0 & 0.75 \\
\hline
\end{tabular}

mortars, summarized in Table 2, were realized according to the European Norm EN 998-1 [36] and taking into account the experience acquired during previous works on mortars containing different PCMs [37-40].

Referring to "water saturation" reported in Table 2, this parameter represents the water used to saturate the LS aggregates, which have a high porosity, to prevent them from absorbing water needed in the manufacture of mortars. In the case of LS/ PEG-60 composite, the saturation step was not required since the pores of Lecce stone were already saturated by PEG.

\subsection{Characterization of LS, PEG and LS/PEG composite}

To determine the pore size and the pore distribution of the Lecce Stone employed in this study, a mercury intrusion porosimeter (Thermo Scientific) was used. This instrument is equipped with two units; the first one works in low pressure regime $(140 \mathrm{~Pa})$ to measure macropores, the second one in high pressure regime (240 $\mathrm{Pa}$ ) to measure micropores. The preparation of the samples as well as the execution of the tests were made in accordance with the recommendations reported in the code [41]. Analogously, the specimens for the analysis were taken from a single stone element, cut with a hand-saw. Since LS is a sedimentary lithotype, inhomogeneity in both its open porosity and distribution of pore size can be observed, even though the samples come from the same rock block. To exclude large variations due to the stone features, the investigations by MIP were performed in triplicate.

In order to identify the more appropriate temperature to achieve a satisfactory inclusion of liquid PEG 1000 in the pores of Lecce stone, the rheological characterization of PEG was carried out in a strain controlled rheometer (Ares TA Instrument) at different temperatures. The viscosity was measured using a parallel plate geometry (radius $25 \mathrm{~mm}$ ) in steady state mode, the shear rate ranging from 0.5 to $100 \mathrm{~s}^{-1}$. The rheological experiments were carried out at different temperatures (from $33^{\circ} \mathrm{C}$ to $60^{\circ} \mathrm{C}$ ); for each test temperature, the rheological experiments were repeated at least three times, to check the repeatability of results.

The chemical characterization of each LS/PEG systems (i.e., LS/PEG-10, LS/PEG30, LS/PEG-60) was performed with a FT-IR ThermoNicolet Nexus spectrometer, equipped with a deuterated triglycine sulfate (DTGS) detector. For comparison, the neat PEG and LS were also analyzed. The samples were mixed with $\mathrm{KBr}$ (suitable for infrared analysis and provided by Mallinckrodt Baker Chemical Inc.) and compacted in pellets $13 \mathrm{~mm}$ in diameter. The $\mathrm{KBr}$ pellets were analyzed in transmission mode, immediately after their preparation. The experiments were performed in triplicate on each system analyzed. The spectra were acquired in the range of $4000-400 \mathrm{~cm}^{-1}$, with a resolution of $4 \mathrm{~cm}^{-1}$ and 32 scans per measurement; the background spectrum was collected on a $\mathrm{KBr}$ control pellet. All the FT-IR data were processed with the OMNIC 8.1 software (Thermo Fisher Scientific Inc).

The thermal properties of both the pure PEG and the produced LS/PEG systems (i.e., LS/PEG-10, LS/PEG-30, LS/PEG-60) were measured with a DSC1 (Star ${ }^{\mathrm{e}}$ System, Mettler Toledo) instrument. In order to evaluate the thermal properties of the produced LS/PEG composites, each sample was subjected to sequential thermal cycles, between $-10^{\circ}$ to $100^{\circ} \mathrm{C}$ on heating, and from $100^{\circ}$ to $-10^{\circ} \mathrm{C}$ on cooling. The heating and cooling rates used during the DSC analyses were $10^{\circ} \mathrm{C} / \mathrm{min}$; the tests were performed under nitrogen atmosphere (flow rate: $60 \mathrm{ml} \mathrm{min}{ }^{-1}$ ). The amount of each sample was between 10 and $20 \mathrm{mg}$ and aluminum crucibles were used. Three samples were analyzed for each formulation, and the results averaged.

The thermal degradation process of PEG-based PCMs (i.e., PEG, LS/PEG-10, LS/ PEG-30, LS/PEG-60) was studied through a TGA/DSC1 (Star ${ }^{\mathrm{e}}$ System) instrument, produced by Mettler Toledo. TGA analyses were conducted at a heating rate of $10^{\circ} \mathrm{C} / \mathrm{min}$, in the range $25^{\circ}-450^{\circ} \mathrm{C}$, once again under nitrogen atmosphere (flow rate: $50 \mathrm{ml} \mathrm{min}^{-1}$ ). The amount of each sample was between 10 and $20 \mathrm{mg}$, charged in an alumina crucible. For checking the repeatability of results, the thermogravimetric test was repeated three times for each system.

The morphology and microstructure of both the pure LS and the form-stable LS/ PEG (for all of them, i.e., LS/PEG-10, LS/PEG-30 and LS/PEG-60) were analyzed using a Scanning Electronic Microscope (SEM, Carl Zeiss Auriga40 Crossbeam instrument). This instrument is combined with energy dispersive spectroscopy (EDS) in order to analyze the chemical composition, i.e. qualitative/quantitative element analyses, of the specimens. The investigations were performed under vacuum on samples without metallization, using a beam accelerating voltage of $20 \mathrm{kV}$ and the secondary electron detector. Distribution maps of elements were acquired on a sample area of $710 \times 600 \mu \mathrm{m}^{2}$ (on average 1678 data per map). For the overall investigated area, the cumulated entire spectrum was also retrieved. Each test was repeated at least three times.

In order to introduce the selected aggregates, that is LS/PEG-60, into the fresh mix of the mortar, the density of this PCM system, according to European Standard EN 1097-6 [42], was determined. For comparison purposes, the same tests were repeated on the pure stone granules (i.e., without PEG). The density determination was repeated on three specimens for each system, averaging the results.

\subsection{Characterization of the aerial lime mortars}

The workability of the different mortars produced, reported in Table 2, in fresh state was evaluated through the flow table method, according to the European standard EN 1015-3 [43].

The mechanical characteristics, in flexural and compressive mode, of the produced mortars were determined according to the European standard EN 1015-11 [44] using a Lloyd dynamometer instrument. For each mortar composition, 3 prismatic specimens $\left(40 \times 40 \times 160 \mathrm{~mm}^{3}\right)$ were prepared by casting the fresh mortars in iron molds. After a first curing stage of 2 days, the specimens were demolded and left for additional 26 days in a storing room at standard temperature $\left(25^{\circ} \mathrm{C}\right)$ and humidity (50\%). The flexural tests were, then, performed at a speed of $6 \mu \mathrm{m} / \mathrm{s}$, while the compressive tests at a speed of $12 \mu \mathrm{m} / \mathrm{s}$.

The thermal conductivity was determined on 28-days cured AL_LS ${ }_{800}$ SP and AL_LS/PEG 800 SP mortars using a C-Therm TCi Thermal Properties Analyzer, according to ASTM standard D7984 [45]. The Modified Transient Plane Source (MTPS) sensor operates in a temperature range between $-50^{\circ} \mathrm{C}$ and $200{ }^{\circ} \mathrm{C}$; it is suitable for testing solids, powders and pastes. On the surface of each specimen, a contact agent was applied; the specimen was, then, placed on the sensor. The contact agent was necessary to guarantee a perfect adhesion between the sample and the sensor. For the same reason, a weight was placed on the specimen. The measurements were performed at room temperature on three samples for each mortar composition.

\section{Results and discussion}

\subsection{Characterization of LS, PEG 1000 and LS/PEG composite systems}

The pore size distribution curve of LS, determined by mercury intrusion porosimetry (MIP), is shown in Fig. 4. Most of pore sizes (61\%) lied between radii of 0.25 and $2 \mu \mathrm{m}$. The average pore radius was $0.054 \pm 0.036 \mu \mathrm{m}$ and the total open porosity was $30.33 \pm 0.99 \%$. Thanks to these porosimetric properties, LS is prone to easily absorb liquid PEG, providing a PCM suitable to be added as aggregate in mortars. The pore distribution was found similar for each measurement, the porosity values were reproducible and comparable to those reported in literature $[46,47]$.

In Fig. 5 the results of rheological measurements, performed on PEG 1000 in steady-state mode, were displayed from 0.5 to $100 \mathrm{~s}^{-1}$ to illustrate its steady shear viscosity as a function of the test temperature.

The viscosity of PEG was characterized by a pseudo-plastic behavior, typical of thermoplastic polymers, and it decreased with increasing temperature, as expected [48]. At temperatures higher than $40^{\circ} \mathrm{C}$, comparable values of viscosity were obtained. Starting from these results and taking into account that, as described in detail below, the melting process of pure PEG was already completed at $55^{\circ} \mathrm{C}$, a temperature of $60^{\circ} \mathrm{C}$ was judged suitable to incorporate PEG into the Lecce stone.

The neat materials and the PCM composites were characterized by FT-IR to investigate the chemical compatibility and the possible interactions between PEG and Lecce stone. The acquired spectra are reported in Fig. 6. The FT-IR spectrum of the stone revealed 


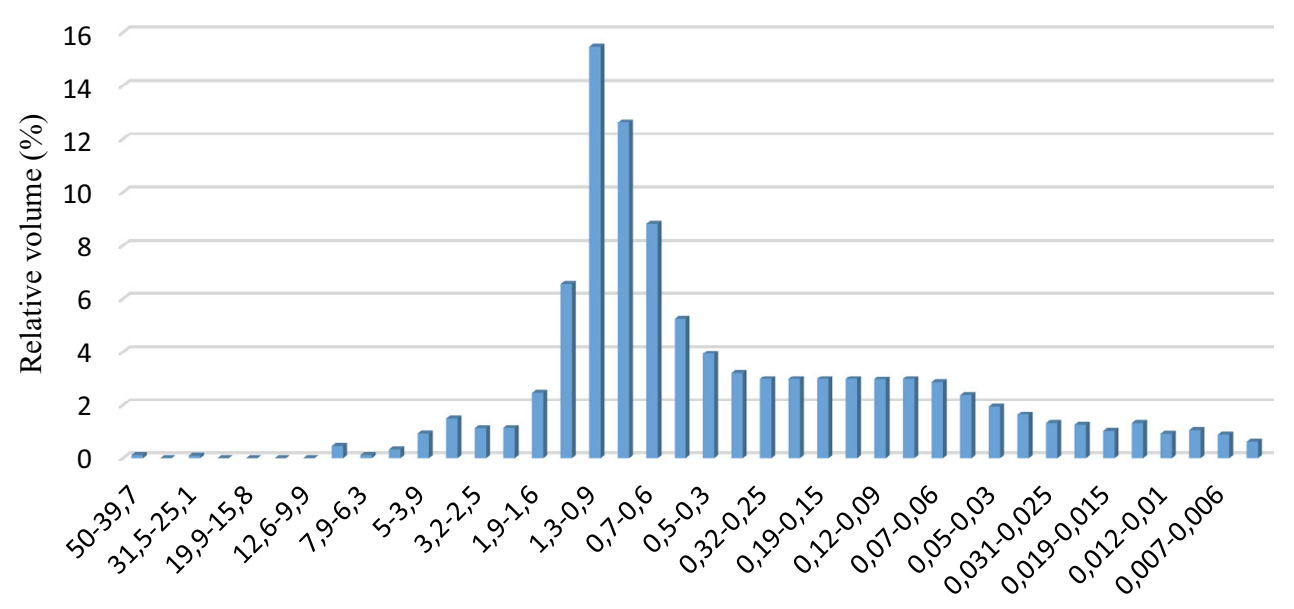

Pore radius range $(\mu \mathrm{m})$

Fig. 4. Pore size distribution of Lecce Stone.

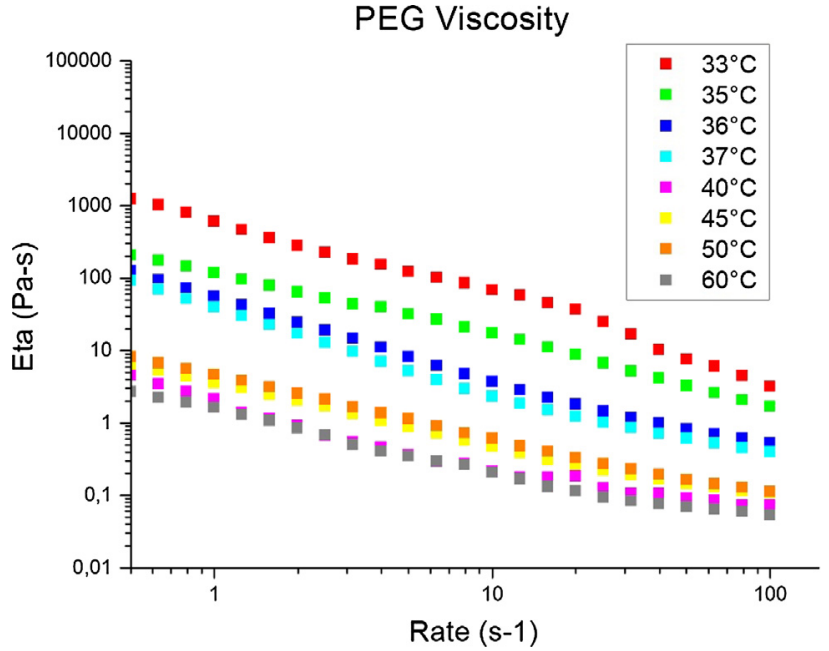

Fig. 5. Shear viscosity versus shear rate of PEG 1000 measured st different temperatures.

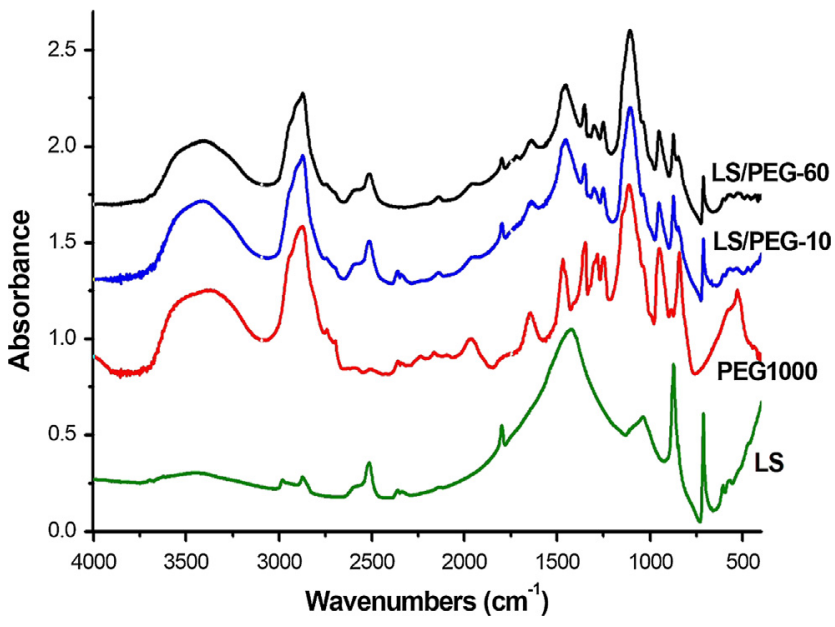

Fig. 6. FT-IR spectra of pure components, LS and PEG, and PCM-stone composites.

the presence of calcite $\left(1797,1420,872\right.$ and $\left.713 \mathrm{~cm}^{-1}\right)$ and low amounts of silicate minerals $\left(1035 \mathrm{~cm}^{-1}\right)$. Many peaks characterized the spectrum of PEG1000 [31]; among them, the peak centered at $1104 \mathrm{~cm}^{-1}$ is due to the $\mathrm{C}-\mathrm{O}$ stretching vibration, the absorbance bands at 2873 and $950 \mathrm{~cm}^{-1}$ are attributed to the stretching vibration of the $-\mathrm{CH}_{2}$ groups, the broad signal around $3369 \mathrm{~cm}^{-1}$ corresponds to the $\mathrm{O}-\mathrm{H}$ stretching vibration.

In the spectra of the composite materials (i.e., LS/PEG-10 and LS/ PEG-60), no new signal was observed other than the typical bands of PEG and Lecce stone. The absence of new peaks proved that no chemical interaction occurred between PEG and the stone material. Actually, slight shifts in some characteristic absorption peaks of PEG were observed in the spectra of the composites. In particular, the peak at $1114 \mathrm{~cm}^{-1}$ shifted to $1104 \mathrm{~cm}^{-1}$ and the band at $3369 \mathrm{~cm}^{-1}$ shifted to $3414 \mathrm{~cm}^{-1}$. This behavior highlighted that some physical attractions, including hydrogen bonds, took place between the two components [49-51]. Comparable results were obtained for LS/PEG-10 and LS/PEG-60 systems, i.e. irrespective of the impregnation time.

The observed physical interactions can have positive effects on the stability of the prepared PCM composite. In fact, hydrogen bonding interactions, capillary action and surface tension forces largely contribute to the stabilization of the form-stable PCM. The PEG molecules are easily retained into pores of the stone because of these forces and their freedom of motion is strongly restricted; therefore, the leakage of the melted PEG from the composite is prevented [51,52].

To evaluate the LHTES (Latent Heat Thermal Energy Storage) properties of PCM-stone composites, the measurement of their melting temperature and latent heat capacity is an important aspect. Fig. 7 shows the DSC thermograms of pure PEG and of PCM-stone composites, including both heating and cooling cycles. The thermal study of LS without PEG was not included because, in the investigated temperature range, the stone does not exhibit thermal phenomena. The phase change temperatures and the related latent heat capacities are summarized in Table 3.

As reported in Table 3 and shown in Fig. 5, PEG exhibited an endothermic peak centered at around $43{ }^{\circ} \mathrm{C}$ during the DSC heating run and an exothermic peak at about $23^{\circ} \mathrm{C}$ during the cooling cycle. The PCM-stone composites, LS/PEG-10, LS/PEG-30, LS/PEG60 , displayed an endothermic (melting) peak at around $38-39{ }^{\circ} \mathrm{C}$ and exothermic (crystallization) peak at about $18-20^{\circ} \mathrm{C}$. The different times used to impregnate LS granules with PEG had a very small influence on the melting/crystallization temperatures. The DSC curves observed for LS/PEG composites in both the melting and crystallization processes are shifted toward lower temperatures, probably due to surface interactions between PEG component and the LS porous substrate. Weak physical interactions 


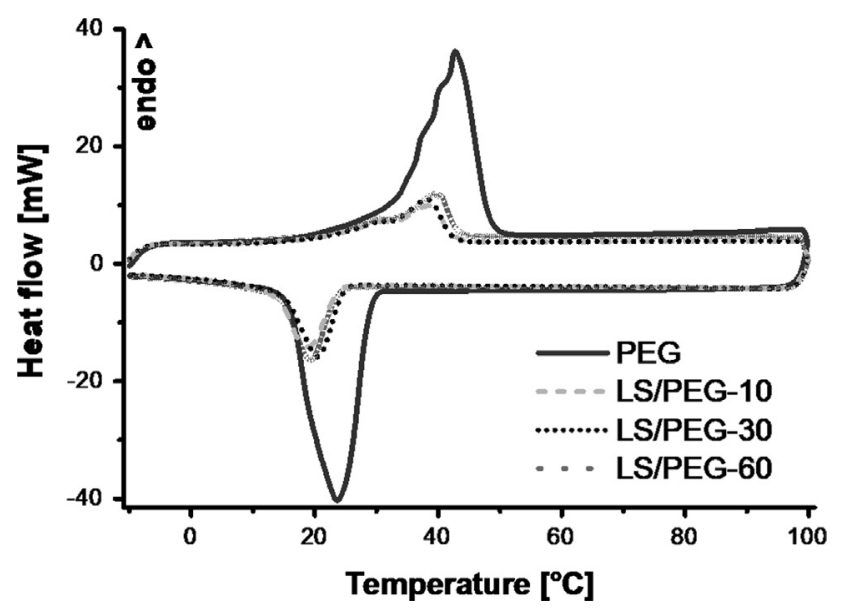

Fig. 7. DSC curves of the pure PEG and of PCM-stone composites.

(i.e., hydrogen bonds, capillary forces, surface adsorption) between PEG and porous substrates are influential on the phase changes behavior, especially on the crystallization process, leading to phase change temperatures slightly lower than those of pristine PEG [53-57].

As already underlined, in order to be used in building applications, a PCM must display a suitable range of phase transition temperatures. The phase change temperatures of the produced form-stable LS/PEG composites, as illustrated in Fig. 5 and from the observation of results listed in Table 3, could be considered favorable if the PCM will be used as Thermal Energy Storage material in the exterior wall of buildings and/or included in indoor mortars employed in buildings located in warm (for instance Mediterranean) regions [31].

The phase change enthalpy (i.e., heat absorbed from crystalline to melt state and released from melt state to crystalline one) is a critical factor in PCMs and can be used as a measure to assess their Thermal Energy Storage capacity. The selected PCM showed a melting/crystallization enthalpy of about $129-130 \mathrm{~J} / \mathrm{g}$. The values found in the present study are roughly comparable with those calculated for the same pure material (PEG 1000) by other researchers, i.e.: $143.2 \mathrm{~J} / \mathrm{g}$ and $166.7 \mathrm{~J} / \mathrm{g}$ as melting and crystallization heats, respectively, as reported by and Karaman et al., and $144.4 \mathrm{~J} / \mathrm{g}$ and $154.4 \mathrm{~J} / \mathrm{g}$ as melting and crystallization enthalpies, respectively, reported by Kou et al. [31,32]. An expected pronounced difference between the melting and crystallization enthalpies of PEG and of PEG-stone composites was measured. The different LS/PEG composites, produced by varying only the impregnation time, exhibited similar melting/crystallization enthalpies, ranging from 26 to $31 \mathrm{~J} / \mathrm{g}$. Although many factors may cause a decline in phase-change enthalpies, these results are in accordance with the lower amount of PEG into the LS/PEG composite samples. The slight difference between melting and crystallization heats measured for LS/PEG-60 can be ascribed to small imprecision in the calculation of enthalpies.

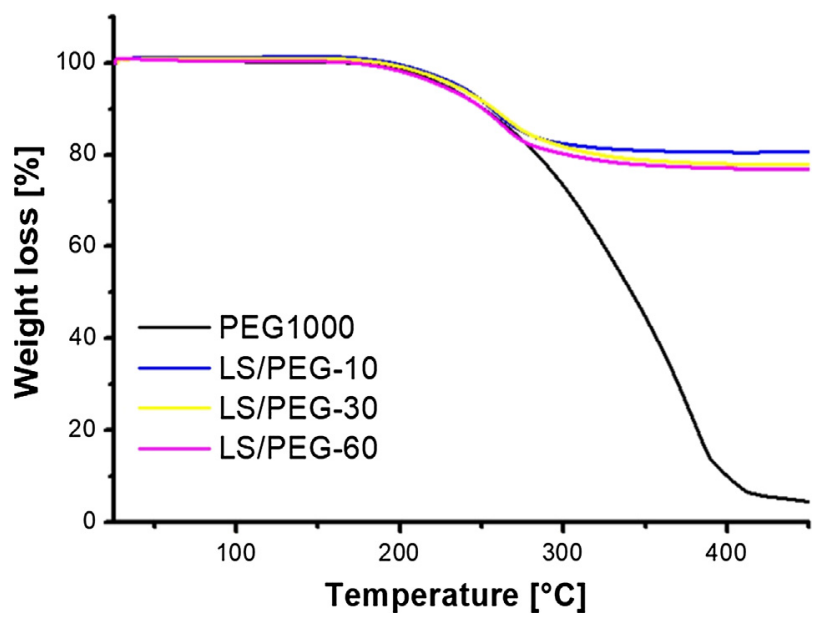

Fig. 8. TGA curves of the pure PEG and PCM-stone composites.

According to the values of phase change latent heat collected and reported in [31] for different PCM composites, the melting/ crystallization enthalpies measured in the present study for LS/PEG composites are in line with those measured for different thermally efficient PCM systems.

The DSC results found on the pure PEG, finally, were employed to select the more appropriate temperature to accomplish the process of absorption of fluid PEG into the LS flakes. It was found, in fact, that the melting process has been completed at about $55^{\circ} \mathrm{C}$; $60^{\circ} \mathrm{C}$, therefore, was selected as process temperature, as reported in paragraph 2.2 .

Thermal resistance is another important property for a PCM for TES application. TGA was used to evaluate this parameter and, at the same time, also the degradation temperatures in a nonoxidative atmosphere. The obtained results are shown in Fig. 8 and briefly summarized in Table 4, where "onset" and "endset" represent the initial and final temperatures of the degradation process, respectively. Once again, the values calculated for PEG 1000 are nearly comparable with those found for the same material in previous works [31,32].

As shown in Fig. 8, for pure PEG, as well as for PCM-stone composites, the degradation process started around $220^{\circ} \mathrm{C}$. On the other hand, the final temperatures of the degradation process of PCM-stone composites were appreciably lower (of more than

Table 4

Degradation temperatures and percentage composition of PEG and PCM-stone composites evaluated by TGA.

\begin{tabular}{lllll}
\hline Sample & Onset $\left({ }^{\circ} \mathrm{C}\right)$ & Endset $\left({ }^{\circ} \mathrm{C}\right)$ & Residual $(\%)$ & Amount of PEG $(\%)$ \\
\hline PEG1000 & $220.2 \pm 1.2$ & $401.1 \pm 1.1$ & $1.7 \pm 0.5$ & $98.3 \pm 0.5$ \\
LS/PEG-10 & $219.1 \pm 0.9$ & $286.0 \pm 1.3$ & $80.5 \pm 0.9$ & $19.5 \pm 1.5$ \\
LS/PEG-30 & $218.2 \pm 1.1$ & $296.1 \pm 0.9$ & $78.0 \pm 1.1$ & $22.0 \pm 2.1$ \\
LS/PEG-60 & $219.1 \pm 1.2$ & $292.6 \pm 1.2$ & $77.0 \pm 1.0$ & $23.0 \pm 1.4$ \\
\hline
\end{tabular}

Table 3

LHTES properties of the selected PCM and produced PCM-stone composites.

\begin{tabular}{|c|c|c|c|c|c|c|}
\hline \multirow[t]{2}{*}{ Sample } & \multicolumn{3}{|l|}{ Heating } & \multicolumn{3}{|l|}{ Cooling } \\
\hline & Onset $\left({ }^{\circ} \mathrm{C}\right)$ & $\operatorname{Tm}\left({ }^{\circ} \mathrm{C}\right)$ & $\Delta \mathrm{Hm}(\mathrm{J} / \mathrm{g})$ & Onset $\left({ }^{\circ} \mathrm{C}\right)$ & $\operatorname{Tc}\left({ }^{\circ} \mathrm{C}\right)$ & $\Delta \mathrm{Hc}(\mathrm{J} / \mathrm{g})$ \\
\hline PEG1000 & $35.1 \pm 1.7$ & $42.8 \pm 1.1$ & $129.3 \pm 1.2$ & $28.9 \pm 1.1$ & $23.6 \pm 1.2$ & $129.8 \pm 0.8$ \\
\hline LS/PEG-10 & $28.6 \pm 0.9$ & $38.4 \pm 0.8$ & $28.2 \pm 1.1$ & $23.8 \pm 1.4$ & $18.5 \pm 1.1$ & $28.7 \pm 1.2$ \\
\hline LS/PEG-30 & $29.6 \pm 1.1$ & $38.2 \pm 1.2$ & $31.1 \pm 1.1$ & $24.6 \pm 1.0$ & $20.4 \pm 0.9$ & $31.3 \pm 0.9$ \\
\hline LS/PEG-60 & $31.7 \pm 1.2$ & $39.3 \pm 0.7$ & $27.7 \pm 0.9$ & $23.5 \pm 0.7$ & $19.4 \pm 0.9$ & $26.2 \pm 1.1$ \\
\hline
\end{tabular}


$100{ }^{\circ} \mathrm{C}$ ) than that measured on PEG in isolation. This result could be ascribed to the low amount of PEG (around $20-22 \%$, see later) in the samples subjected to the TGA test. Nevertheless, from thermo-gravimetric analysis it can be inferred that the produced PCM composites display a thermal resistance and a thermal stability still suitable for the intended purposes, as reported in literature for efficient PCMs based on different materials [7,50,58-60]. The slightly different impregnation level of PEG into LS granules did not significantly affect these properties.

TGA analysis was also applied to evaluate the amount of PEG polymer absorbed into the LS. The PEG content into the LS granules was calculated as the percentage of mass loss at the end of the TGA tests, i.e., at $450{ }^{\circ} \mathrm{C}$ when the complete degradation of the polymer was achieved, as observed in the TGA thermogram for pure PEG. This value was approximately $20 \%$ for all the PCM-stone composites (Table 4), with a slight increase for longer impregnation times.

The thermal properties measured by DSC and TGA proved that the produced PEG-stone composites, and in particular the system produced employing the longest impregnation time (i.e., LS/PEG60 ), display a suitable thermal behavior. The observed parameters were, in fact, roughly in line with those reported in the literature for efficient PEG-based PCMs, as it can be inferred by the comparison reported in Table 5. It must be bared in mind that the melting/ crystallization enthalpies reported in Table 5 refer to the total mass of the PEG-based PCM composites. For each system, it is reported in the same table the content of PEG, that varies appreciably in the different studies; for such a reason, the values of heats of melting and crystallization differ in the different studies.

In conclusion, the prepared LS/PEG can be considered as promising candidate for application as PCMs for energy saving in buildings.

SEM observations were used to investigate the impregnation of the LS granules. Due to their small dimensions, the cutting of the specimens was impracticable. Therefore, it was not possible to observe the impregnation of the internal part of each granule. However, the results of EDS analyses allowed to have an indication

Table 5

Comparison of thermal properties of the PCM composite under investigation with those found in previous studies on different PEG-based PCMs.

\begin{tabular}{|c|c|c|c|c|c|c|c|c|}
\hline & PEG content (\% mass) & $\operatorname{Tm}\left({ }^{\circ} \mathrm{C}\right)$ & Tc $\left({ }^{\circ} \mathrm{C}\right)$ & $\Delta \mathrm{Hm}(\mathrm{J} / \mathrm{g})$ & $\Delta \mathrm{Hc}(\mathrm{J} / \mathrm{g})$ & Onset $\left({ }^{\circ} \mathrm{C}\right)$ & Endset $\left({ }^{\circ} \mathrm{C}\right)$ & Ref. \\
\hline PEG 1000/expanded graphite & 87.5 & 23.96 & 18.49 & 108.22 & 101.92 & 351 & 420 & [61] \\
\hline PEG $1000 / \mathrm{SiO}_{2}$ & 80 & 36.8 & 21.5 & 113.6 & 115.4 & - & - & [62] \\
\hline PEG 1000/diatomite & 50 & 27.70 & 32.19 & 87.09 & 82.22 & 245 & 500 & [31] \\
\hline PEG 1000/montmorillonite & 44 & 35.8 & 21.3 & 104.8 & 107.0 & 310 & 450 & [63] \\
\hline PEG 1000/montmorillonite & 28 & 39.0 & 17.6 & 18.7 & 17.4 & - & - & [63] \\
\hline PEG 1000/carbonate stone (LS/PEG-60) & 23 & 39.3 & 19.4 & 27.7 & 26.2 & 219.1 & 292.6 & This work \\
\hline
\end{tabular}

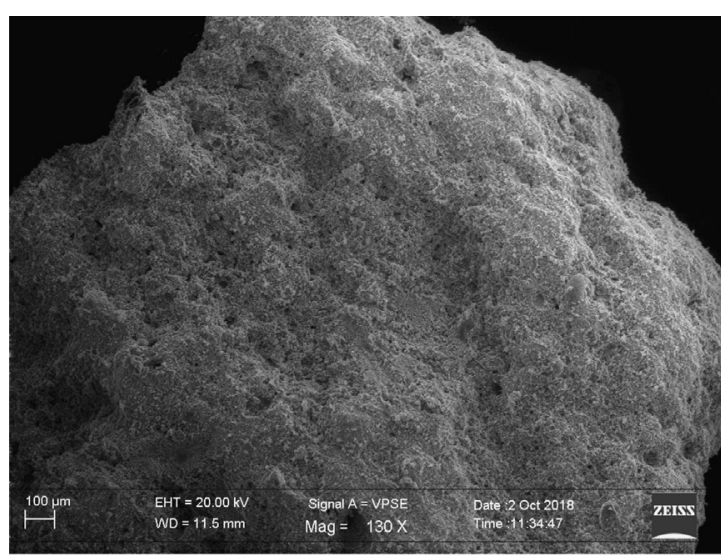

(a)

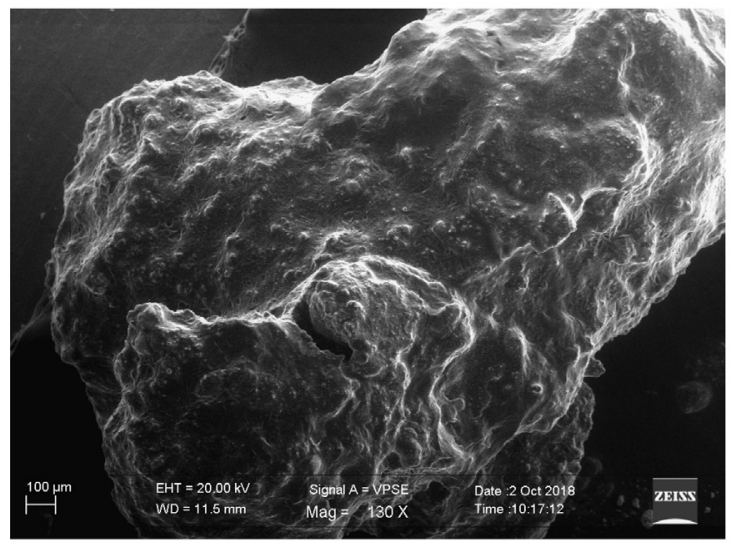

(c)

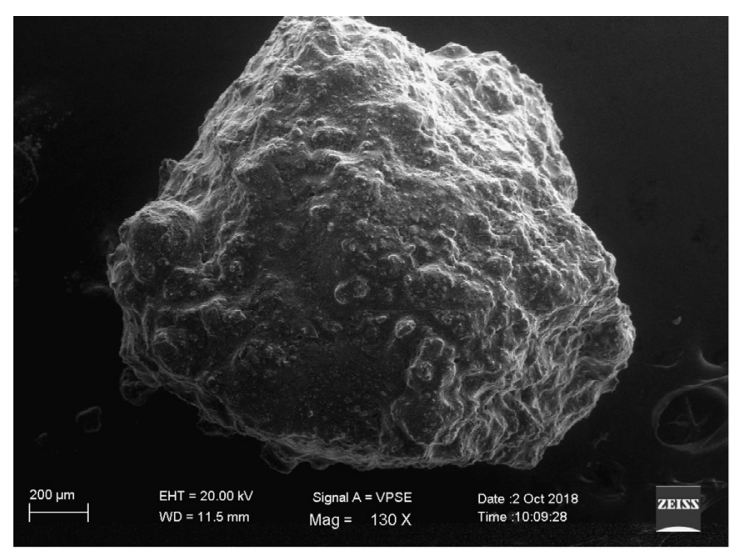

(b)

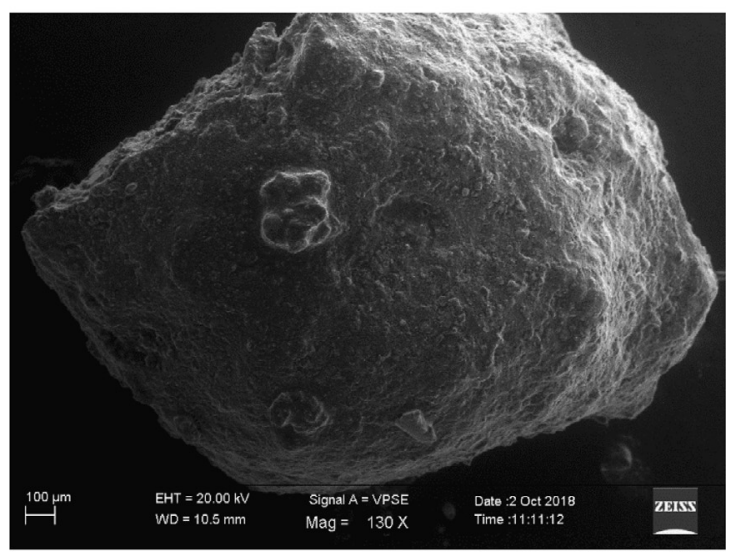

(d)

Fig. 9. SEM images of untreated and treated stone granules: (a) LS, (b) LS/PEG-10, (c) LS/PEG-30, and (d) LS/PEG-60. 
of the penetration of PEG into the stone pores, even though the same analysis performed on the specimens cannot provide quantitative amounts.

In Fig. 9 the SEM images of the untreated and treated granules of LS are compared. The surface of the pure stone appeared rough, with evident small cavities due to the pore structure (Fig. 9a). After the impregnation, the surface appeared smoother because of the presence of PEG. In the samples treated for $10 \mathrm{~min}$, the morphology of the stone and few empty cavities were still recognizable (Fig. 9b). A polymeric coating accumulated on the surface of the LS/PEG-30 system (Fig. 9c), hiding the stone beneath, while a more uniform impregnation was observed in the case of samples treated for $60 \mathrm{~min}$ (Fig. 9d).

The EDS results, reported in Fig. 10, confirmed these findings. In all the samples, $\mathrm{Ca}, \mathrm{O}, \mathrm{Si}, \mathrm{C}, \mathrm{Mg}, \mathrm{P}$ and $\mathrm{Al}$ elements were detected. The element Ca can only derive from the stone support, while $C$ can be due to both stone and PEG. Therefore, larger quantities of $C$ were expected in the LS/PEG composites and, thus, the C/Ca ratio was used to evaluate the presence of PEG in the samples. For the pure stone this value was 0.4 ; increases to 4.3 and 11.1 were measured for impregnation times of 10 and $30 \mathrm{~min}$, respectively; the $\mathrm{C} / \mathrm{Ca}$ ratio declined for longer period of treatment (i.e., $60 \mathrm{~min}$ ). The very high ratio measured on the LS/PEG-30 suggested a substantial accumulation of PEG onto the surface of the LS granules. On these samples, in fact, the EDS maps highlighted a lower

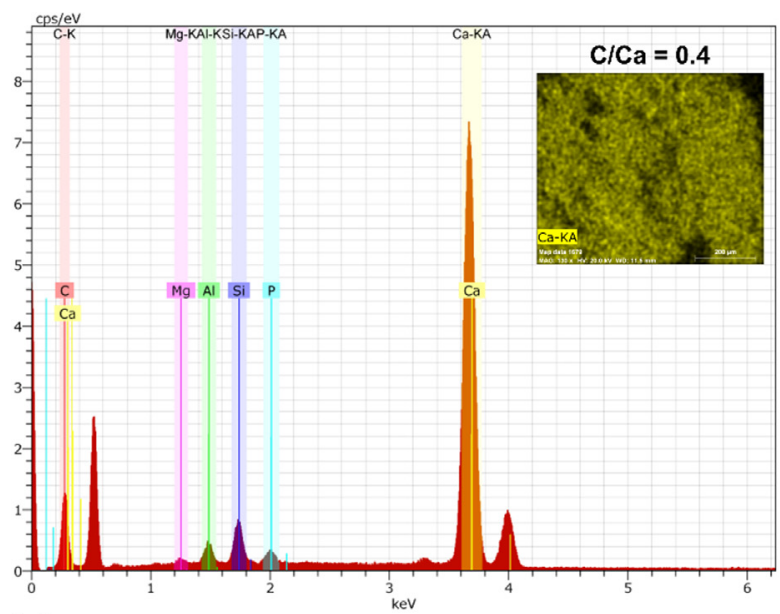

(a)

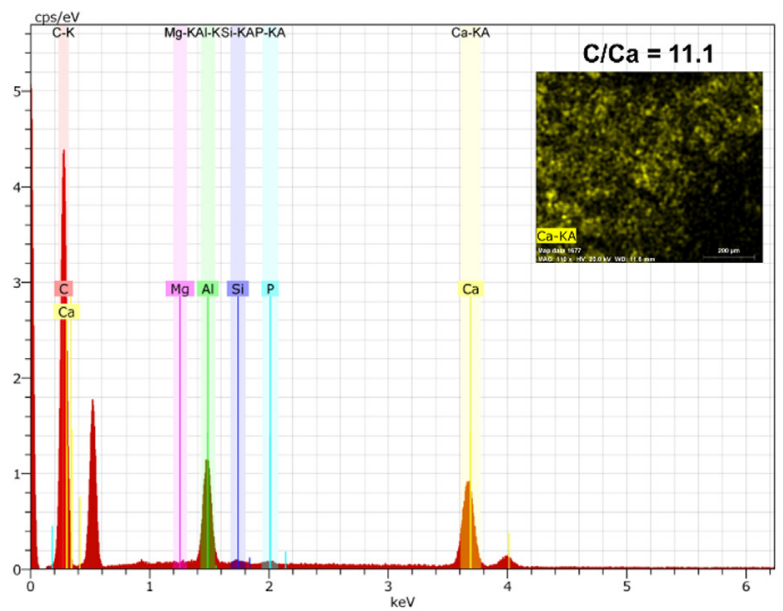

(c) intensity of the Ca signal as a consequence of the polymer covering. The observed behavior suggested that, although very similar amounts of PEG were absorbed after 30 and $60 \mathrm{~min}$, the prolonged impregnation time was useful to promote a better PEG uptake into the stone.

The results of the chemical, thermal and morphological characterization allowed to chose the LS/PEG-60 system as inert PCM for the mortar formulations. Actually, no remarkable differences were observed between the prepared composites. However, 60 min for LS impregnation assured a deeper penetration of PEG, as well as greater PCM loading, which potentially yield better thermal behavior [64], reduced leakage and good final performances.

To tailor the mortar compositions, densities of LS and of LS/PEG60 were measured. To the same aim, the porosity accessible to water in Lecce Stone was evaluated. A density of $2957 \mathrm{~kg} / \mathrm{m}^{3}$ and a porosity accessible to water of $33.6 \%$ were measured in LS; LS/ PEG-60 exhibited a density of $3724 \mathrm{~kg} / \mathrm{m}^{3}$.

\subsection{Characterization of mortar formulations}

Aerial lime-based mortars are commonly used as mortars for restoration of historic buildings. In such applications, in fact, the use of materials similar to those originally used is mandatory: from this point of view, lime-based mortars represent the best solution. Referring to the same repair applications, the mortars based on

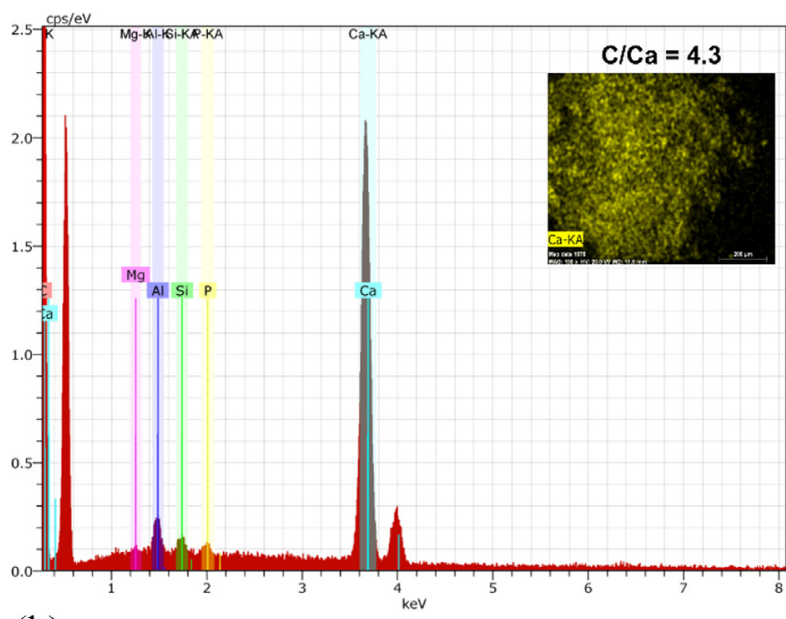

(b)

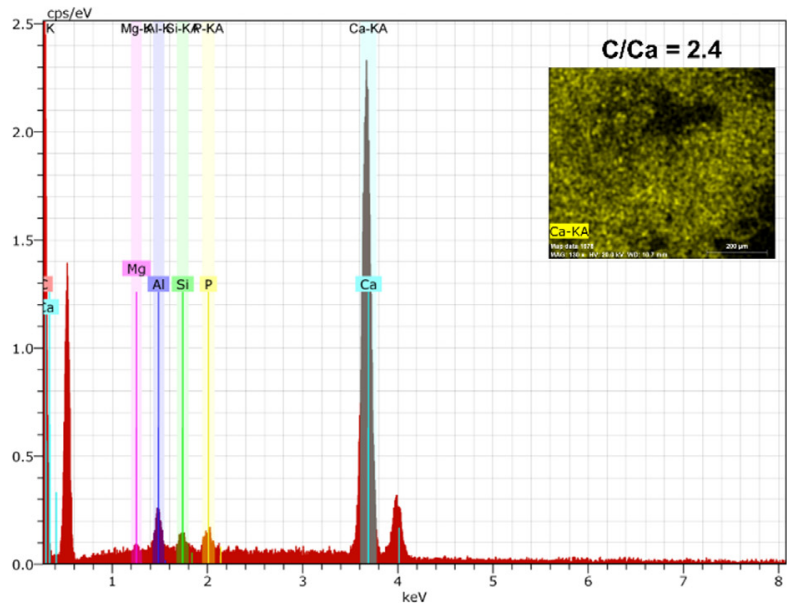

(d)

Fig. 10. EDS spectra and map of Ca for untreated and treated stone granules: (a) LS, (b) LS/PEG-10, (c) LS/PEG-30, and (d) LS/PEG-60. The C/Ca ratio is reported for each sample. 
Portland cement, in fact, display some degree of incompatibility with the pre-existing support materials of old buildings.

Generally speaking, aerial lime is suitable to manufacture mortars for both masonry and bricks. With a proper selection of base components and of the formulation composition, the aerial limebased mortars exhibit good workability in fresh state and adequate mechanical properties.

In the present work, the workability test on the produced aerial lime-based mortars was first performed. In Table 6 the workability values for the developed mortars are reported. It must be kept in mind that the appropriate value of workability for aerial limebased mortars must be in the range of $160-180 \mathrm{~mm}[64,65]$.

It is well known that a proper content of water is necessary to assure a good workability of the mortar formulation and that this amount should not be excessive: it can lead, in fact, to a high porosity in the mortar and, as a consequence, to unsuitable mechanical properties [65]. Therefore, superplasticizers (SP) are commonly used as they improve the workability of the mortars even using limited amounts of water. As reported in Table 6, after a proper preliminary study, it was possible to obtain an appropriate value of workability for all the formulations analyzed.

In Table 7, the results of flexural and compressive tests performed on the different produced mortars are presented.

As expected, the use of a superplasticizer in a mortar containing LS as aggregate allowed achieving increased values for both flexural and compressive strengths.

According to the results reported in Table 7, a decrease in the flexural and compressive strengths of aerial lime-based mortars is experienced as a consequence of the introduction of the PCM composite and of the greater content of water requested by AL_LS/PEG ${ }_{500}$ composition. The use of a superplasticizer and of a higher amount of binder, on the other hand, allowed achieving better mechanical performance, in terms of both flexural and compressive strengths, even in the mortars containing LS/PEG composite. However, lower strengths were found for this formulation in comparison to the same formulation not containing LS/PEG composite, i.e. $\mathrm{AL} \_\mathrm{LS}_{800} \mathrm{SP}$.

Taking into account the intended application of the produced mortars in the field of constructions, it must be underlined that they should have a minimum classification of CS II based on the compressive strength, according to the standard NP EN 998-1. The mortars produced in our study, on the other hand, possess

Table 6

Values of workability of the produced mortars, whose composition is reported in Table 2.

\begin{tabular}{|c|c|}
\hline System & Workability (mm) \\
\hline AL_LS $\mathrm{L}_{500}$ & 161 \\
\hline AL_LS/PEG 500 & 170 \\
\hline AL_LS ${ }_{500} \_S P$ & 173 \\
\hline AL_LS $800 \_S P$ & 175 \\
\hline AL_LS/PEG $800 \_S P$ & 180 \\
\hline
\end{tabular}

Table 7

Mechanical properties measured in flexural and compressive mode on the produced aerial lime-based mortars.

\begin{tabular}{llll}
\hline System & $\begin{array}{l}\text { Flexural } \\
\text { strength } \\
(\mathrm{MPa})\end{array}$ & $\begin{array}{l}\text { Compressive } \\
\text { strength } \\
(\mathrm{MPa})\end{array}$ & $\begin{array}{l}\text { Thermal } \\
\text { conductivity } \\
(\mathrm{W} / \mathrm{m} \cdot \mathrm{K})\end{array}$ \\
\hline AL_LS $_{500}$ & $0.51 \pm 0.10$ & $0.52 \pm 0.04(\mathrm{CS} \mathrm{I})$ & - \\
AL_LS/PEG $_{500}$ & $0.20 \pm 0.07$ & $0.24 \pm 0.05(\mathrm{n} . \mathrm{a})$. & - \\
AL_LS & $0.64 \pm 0.03$ & $0.69 \pm 0.09(\mathrm{CS} \mathrm{I})$ & - \\
AL_LS & $0.92 \pm 0.04$ & $1.51 \pm 0.11(\mathrm{CS} \mathrm{I})$ & $0.46 \pm 0.02$ \\
AL_LS/PEO_SP & $0.53 \pm 0.12$ & $1.21 \pm 0.06(\mathrm{CS} \mathrm{I})$ & $0.47 \pm 0.01$ \\
\hline
\end{tabular}

mechanical characteristics not completely adequate (CS I type), even using a higher amount of binder.

The results of thermal conductivity tests performed on some of the produced mortars are again shown in Table 7. According to the definition of thermal mortars [36], both the produced mortars cannot be defined as thermal mortars, being their thermal conductivity values greater than $0.2 \mathrm{~W} / \mathrm{m} \cdot \mathrm{K}$. Furthermore, from the observation of results it can be concluded that the introduction of PEG-based PCM in an aerial lime mortar does not appreciably affect the thermal conductivity of the mortar not containing the PEG, thus the introduction of PEG did not produce a noticeable insulating effect to this kind of mortar.

\section{Conclusions}

In this paper, the production of a PCM (LS/PEG composite) to include in mortars, obtained through the form-stable method, is illustrated. The sustainable PCM composite was produced by impregnation of PEG 1000 polymer into small pieces of Lecce Stone, these latter obtained as a waste product from the production of stone blocks employed in constructions. PEG was selected for this purpose due to its eco-friendly character and for the appropriate thermal properties (suitable phase change temperatures and large phase change enthalpy). The performed rheological measurements confirmed the possibility to obtain PEG in liquid state by heating the polymer at a mild temperature (i.e., $60^{\circ} \mathrm{C}$ ). The porosimetric study performed on the stone, furthermore, demonstrated the suitability of LS to absorb liquid PEG. The impregnation of PEG into the stone was achieved under vacuum. Different impregnation times were employed, in order to identify the most appropriate procedure to achieve an efficient PEG-based PCM. A wide characterization was performed on LS/PEG composites through FT-IR, DSC and TGA analyses, SEM observations and EDS investigations. It was found that an impregnation time of $60 \mathrm{~min}$ allowed to obtain PCM composites that potentially may exhibit better final performance. In LS/PEG-60 samples, in fact, a deeper penetration of PEG was observed, while in LS/PEG-30 and LS/PEG-10 ones most of the applied polymer remained on surface. The presence of PEG mainly inside the pore structure of the stone, on the other hand, would prevent leakage of the softened/melted PEG. The stability of the composite can be also guaranteed by physical interactions between PEG and stone. Capillary action, surface tension and hydrogen bonds are likely to be strong enough to retain the PEG, thus preventing the outflow of the liquid polymer.

LHTES properties and thermal resistance characteristics of the LS/PEG composites, investigated by DSC and TGA analyses, respectively, were found in line with previous studies performed on efficient PEG-based PCMs, and thus suitable for the final purpose of the research.

The selected PCM composite, i.e., LS/PEG-60, was, then, introduced as aggregates to different aerial lime-based mortar compositions, taking as reference the same mortars containing the same amount of Lecce stone without PEG. In order to achieve an adequate workability of the fresh mixtures, and to maintain limited the addition of water, it was necessary to employ a superplasticizer. The addition of the PEG-based PCM caused an unsuitable reduction of compressive and flexural strength values of the aerial lime-based mortars. Essentially unaffected by the presence of PEG resulted the thermal conductivity.

In conclusion, the incorporation method used to include PEG in waste Lecce stone pieces resulted effective in producing sustainable stable LS/PEG PCMs with appropriate LHTES properties. Furthermore, the produced PCM is additionally not toxic or flammable, taking into account that the safety requirement for materials used in buildings is a crucial point. On the other hand, 
the PEG/LS composite appeared to be not suitable as PCM aggregate for the selected binder: the aerial lime-based mortars with incorporation of LS/PEG-60 showed, in fact, some unsatisfactory properties, such as CS I type strength and unchanged thermal conductivity. The ongoing research is focusing on the production of different mortars, based on hydraulic lime, gypsum or cement, incorporating the proposed PCM to assess if it is possible to achieve adequate mechanical properties (at least CS II type strength) along with thermal effects with the addition of LS/PEG composites.

\section{Declaration of Competing Interest}

The authors declare that they have no known competing financial interests or personal relationships that could have appeared to influence the work reported in this paper.

\section{Acknowledgments}

The Authors wish to thank Ing. L. Pascali and Staff of S.I.PRE. S.r. 1. (Cutrofiano, Lecce, Italy) for the technical support and Pitardi Cavamonti, Company (Melpignano, Lecce, Italy) for supplying the Lecce Stone flakes.

\section{References}

[1] V.V. Rao, R. Parameshwaran, V.V. Ram, PCM-mortar based construction materials for energy efficient buildings: a review on research trends, Energy Build. 158 (2018) 95-122, https://doi.org/10.1016/j.enbuild.2017.09.098.

[2] S. Lu, Y. Li, X. Kong, B. Pang, Y. Chen, S. Zheng, L. Sun, A review of PCM energy storage technology used in buildings for the global warming solution, in: X. Zhang, I. Dincer (Eds.), Energy Solut. Combat Glob. Warm., Springer International Publishing, Cham, 2017, pp. 611-644, https://doi.org/10.1007/ 978-3-319-26950-4_31.

[3] D.W. Hawes, D. Banu, D. Feldman, Latent heat storage in concrete, Sol. Energy Mater. 19 (1989) 335-348, https://doi.org/10.1016/0165-1633(89)90014-2.

[4] D.P. Bentz, R. Turpin, Potential applications of phase change materials in concrete technology, Cem. Concr. Compos. 29 (2007) 527-532, https://doi.org/ 10.1016/j.cemconcomp.2007.04.007.

[5] A.R Sakulich, D.P. Bentz, Incorporation of phase change materials in cementitious systems via fine lightweight aggregate, Constr. Build. Mater. 35 (2012) 483-490, https://doi.org/10.1016/j.conbuildmat.2012.04.042.

[6] Z. Zhang, G. Shi, S. Wang, X. Fang, X. Liu, Thermal energy storage cement mortar containing n-octadecane/expanded graphite composite phase change material, Renew. Energy. 50 (2013) 670-675, https://doi.org/10.1016/j. renene.2012.08.024.

[7] B. Xu, Z. Li, Paraffin/diatomite composite phase change material incorporated cement-based composite for thermal energy storage, Appl. Energy 105 (2013) 229-237, https://doi.org/10.1016/j.apenergy.2013.01.005.

[8] Y. He, X. Zhang, Y. Zhang, Preparation technology of phase change perlite and performance research of phase change and temperature control mortar, Energy Build. 85 (2014) 506-514, https://doi.org/10.1016/j. enbuild.2014.09.023.

[9] T. Lecompte, P. Le Bideau, P. Glouannec, D. Nortershauser, S. Le Masson, Mechanical and thermo-physical behaviour of concretes and mortars containing phase change material, Energy Build. 94 (2015) 52-60, https:// doi.org/10.1016/j.enbuild.2015.02.044.

[10] R. Shadnia, L. Zhang, P. Li, Experimental study of geopolymer mortar with incorporated PCM, Constr. Build. Mater. 84 (2015) 95-102, https://doi.org/ 10.1016/j.conbuildmat.2015.03.066.

[11] M. Song, F. Niu, N. Mao, Y. Hu, S. Deng, Review on building energy performance improvement using phase change materials, Energy Build. 158 (2018) 776793, https://doi.org/10.1016/j.enbuild.2017.10.066.

[12] Y. Cui, J. Xie, J. Liu, J. Wang, S. Chen, A review on phase change material application in building, Adv. Mech. Eng. 9 (2017), https://doi.org/10.1177/ 1687814017700828

[13] H.B. Madessa, A review of the performance of buildings integrated with phase change material: opportunities for application in cold climate, Energy Procedia 62 (2014) 318-328, https://doi.org/10.1016/j.egypro.2014.12.393.

[14] T.R. Whiffen, S.B. Riffat, A review of PCM technology for thermal energy storage in the built environment: part I, Int. J. Low-Carbon Technol. 8 (2013) 147-158, https://doi.org/10.1093/ijlct/cts021.

[15] L.F. Cabeza, A. Castell, C. Barreneche, A. de Gracia, A.I. Fernández, Materials used as PCM in thermal energy storage in buildings: a review, Renew. Sustain. Energy Rev. 15 (2011) 1675-1695, https://doi.org/10.1016/j.rser.2010.11.018.

[16] A. Jamekhorshid, S.M. Sadrameli, M. Farid, A review of microencapsulation methods of phase change materials (PCMs) as a thermal energy storage (TES) medium, Renew. Sustain. Energy Rev. 31 (2014) 531-542, https://doi.org/ 10.1016/j.rser.2013.12.033.
[17] M. Hunger, A.G. Entrop, I. Mandilaras, H.J.H. Brouwers, M. Founti, The behavior of self-compacting concrete containing micro-encapsulated Phase Change Materials, Cem. Concr. Compos. 31 (2009) 731-743, https://doi.org/10.1016/j. cemconcomp.2009.08.002.

[18] E. Franquet, S. Gibout, P. Tittelein, L. Zalewski, J.-P. Dumas, Experimental and theoretical analysis of a cement mortar containing microencapsulated PCM Appl. Therm. Eng. 73 (2014) 32-40, https://doi.org/10.1016/j. applthermaleng.2014.06.053.

[19] L. Haurie, S. Serrano, M. Bosch, A.I. Fernandez, L.F. Cabeza, Single layer mortars with microencapsulated PCM: study of physical and thermal properties, and fire behaviour, Energy Build. 111 (2016) 393-400, https://doi.org/10.1016/j. enbuild.2015.11.028.

[20] M.H. Abokersh, M. Osman, O. El-Baz, M. El-Morsi, O. Sharaf, Review of the phase change material (PCM) usage for solar domestic water heating systems (SDWHS): use of phase change material in domestic solar water heating systems, Int. J. Energy Res. 42 (2018) 329-357, https://doi.org/10.1002/ er.3765.

[21] S.A. Memon, Phase change materials integrated in building walls: a state of the art review, Renew. Sustain. Energy Rev. 31 (2014) 870-906, https://doi.org/ 10.1016/j.rser.2013.12.042.

[22] S. Riffat, B. Mempouo, W. Fang, Phase change material developments: a review, Int. J. Ambient Energy 36 (2015) 102-115, https://doi.org/10.1080/ 01430750.2013 .823106$.

[23] X.Q. Zhai, X.L. Wang, T. Wang, R.Z. Wang, A review on phase change cold storage in air-conditioning system: materials and applications, Renew. Sustain. Energy Rev. 22 (2013) 108-120, https://doi.org/10.1016/j. rser.2013.02.013.

[24] D. Zhou, C.Y. Zhao, Y. Tian, Review on thermal energy storage with phase change materials (PCMs) in building applications, Appl. Energy 92 (2012) 593605, https://doi.org/10.1016/j.apenergy.2011.08.025.

[25] A. Fallahi, G. Guldentops, M. Tao, S. Granados-Focil, S. Van Dessel, Review on solid-solid phase change materials for thermal energy storage: molecular structure and thermal properties, Appl. Therm. Eng. 127 (2017) 1427-1441, https://doi.org/10.1016/j.applthermaleng.2017.08.161.

[26] P. Lv, C. Liu, Z. Rao, Review on clay mineral-based form-stable phase change materials: preparation, characterization and applications, Renew. Sustain. Energy Rev. 68 (2017) 707-726, https://doi.org/10.1016/j.rser. 2016.10.014.

[27] A. Rana, P. Kalla, H.K. Verma, J.K. Mohnot, Recycling of dimensional stone waste in concrete: a review, J. Cleaner Prod. 135 (2016) 312-331, https://doi org/10.1016/j.jclepro.2016.06.126.

[28] L. Napolano, C. Menna, D. Asprone, A. Prota, G. Manfredi, LCA-based study on structural retrofit options for masonry buildings, Int. J. Life Cycle Assess. 20 (2015) 23-35, https://doi.org/10.1007/s11367-014-0807-1.

[29] F. Lionetto, M. Frigione, Effect of novel consolidants on mechanical and absorption properties of deteriorated wood by insect attack, J. Cult. Herit. 13 (2012) 195-203, https://doi.org/10.1016/j.culher.2011.09.007.

[30] E. Hocker, G. Almkvist, M. Sahlstedt, The Vasa experience with polyethylene glycol: a conservator's perspective, J. Cult. Herit. 13 (2012) S175-S182, https:// doi.org/10.1016/j.culher.2012.01.017.

[31] S. Karaman, A. Karaipekli, A. Sarı, A. Biçer, Polyethylene glycol (PEG)/diatomite composite as a novel form-stable phase change material for thermal energy storage, Sol. Energy Mater. Sol. Cells 95 (2011) 1647-1653, https://doi.org/ 10.1016/j.solmat.2011.01.022.

[32] Y. Kou, S. Wang, J. Luo, K. Sun, J. Zhang, Z. Tan, Q. Shi, Thermal analysis and heat capacity study of polyethylene glycol (PEG) phase change materials for thermal energy storage applications, J. Chem. Thermodyn. 128 (2019) 259274, https://doi.org/10.1016/j.jct.2018.08.031.

[33] G.F. Andriani, N. Walsh, Petrophysical and mechanical properties of soft and porous building rocks used in Apulian monuments (south Italy), Geol. Soc Lond. Spec. Publ. 333 (2010) 129, https://doi.org/10.1144/SP333.13.

[34] M. Frigione, M. Lettieri, A. Sarcinella, J.B. de Aguiar, Mortars with Phase Change Materials (PCM) and stone waste to improve energy efficiency in buildings, in: M.M.R. Taha (Ed.), Int. Congr. Polym. Concr. ICPIC 2018, Springer International Publishing, Cham, 2018, pp. 195-201, https://doi.org/10.1007/978-3-31978175-4_23.

[35] S. Kamali, Review of free cooling system using phase change material for building, Energy Build. 80 (2014) 131-136, https://doi.org/10.1016/j. enbuild.2014.05.021.

[36] EN 998-1: 2010: Specification for mortar for masonry - Part 1: Rendering and plastering mortar. CEN: Brussels 2010., n.d.

[37] S. Cunha, J. Aguiar, V. Ferreira, A. Tadeu, Mortars based in different binders with incorporation of phase-change materials: physical and mechanical properties, Eur. J. Environ. Civ. Eng. 19 (2015) 1216-1233, https://doi.org/ 10.1080/19648189.2015.1008651.

[38] S. Cunha, J. Aguiar, F. Pacheco-Torgal, Effect of temperature on mortars with incorporation of phase change materials, Constr. Build. Mater. 98 (2015) 89101, https://doi.org/10.1016/j.conbuildmat.2015.08.077.

[39] S. Cunha, J. Aguiar, V. Ferreira, A. Tadeu, A. Garbacz, Mortars with phase change materials - part I: physical and mechanical characterization, Key Eng. Mater. 634 (2014) 22-32, https://doi.org/10.4028/www.scientific.net/ KEM.634.22.

[40] S. Cunha, J. Aguiar, A. Tadeu, Ranking procedure based on mechanical durability and thermal behavior of mortars with incorporation of phase change materials, Mater. Constr. 65 (2015), https://doi.org/10.3989/ mc.2015.07314 e068. 
[41] Normal, Commissione. "Raccomandazione 4/80 Distribuzione del volume dei pori in funzione del loro diametro." 10-10. Istituto Centrale del Restauto Editor, Roma. 1980, n.d.

[42] EN 1097-6: 2013: Tests for mechanical and physical properties of aggregates. Determination of particle density and water absorption, n.d.

[43] European Committee for Standardization (CEN), EN 1015-3 (2004), Methods of test for mortar for mansonry - Part 3: Determination of consistence of fresh mortar (by flow table), n.d.

[44] European Committee for Standardization (CEN), EN 1015-11 (1999), Methods of test for mortar for masonry - Part 11: Determination of flexural and compressive strength of hardened mortar, n.d.

[45] ASTM D7984-16, Standard Test Method for Measurement of Therma Effusivity of Fabrics Using a Modified Transient Plane Source (MTPS) Instrument, ASTM International, West Conshohocken, PA, 2016. n.d. www. astm.org.

[46] S. Bugani, M. Camaiti, L. Morselli, E. Van de Casteele, K. Janssens, Investigation on porosity changes of Lecce stone due to conservation treatments by means of X-ray nano- and improved micro-computed tomography: preliminary results, X-Ray Spectrom. 36 (2007) 316-320, https://doi.org/10.1002/xrs.976.

[47] L. Falchi, E. Balliana, F.C. Izzo, L. Agostinetto, E. Zendri, Distribution of nanosilica dispersions in Lecce stone, (2013) 9.

[48] B. Xu, L. Li, A. Yekta, Z. Masoumi, S. Kanagalingam, M.A. Winnik, K. Zhang, P.M. Macdonald, S. Menchen, Synthesis, characterization, and rheological behavior of polyethylene glycols end-capped with fluorocarbon hydrophobes, Langmuir 13 (1997) 2447-2456, https://doi.org/10.1021/la9607991.

[49] L. Feng, C. Wang, P. Song, H. Wang, X. Zhang, The form-stable phase change materials based on polyethylene glycol and functionalized carbon nanotubes for heat storage, Appl. Therm. Eng. 90 (2015) 952-956, https://doi.org/ 10.1016/j.applthermaleng.2015.07.080.

[50] A. Sarı, Thermal energy storage characteristics of bentonite-based composite PCMs with enhanced thermal conductivity as novel thermal storage building materials, Energy Convers. Manage. 117 (2016) 132-141, https://doi.org 10.1016/j.enconman.2016.02.078.

[51] G.-Q. Qi, C.-L. Liang, R.-Y. Bao, Z.-Y. Liu, W. Yang, B.-H. Xie, M.-B. Yang, Polyethylene glycol based shape-stabilized phase change material for thermal energy storage with ultra-low content of graphene oxide, Sol. Energy Mater. Sol. Cells 123 (2014) 171-177, https://doi.org/10.1016/j.solmat.2014.01.024.

[52] R. Wen, X. Zhang, Z. Huang, M. Fang, Y. Liu, X. Wu, X. Min, W. Gao, S. Huang, Preparation and thermal properties of fatty acid/diatomite form-stable composite phase change material for thermal energy storage, Sol. Energy Mater. Sol. Cells 178 (2018) 273-279, https://doi.org/10.1016/ j.solmat.2018.01.032.

[53] L. Feng, W. Zhao, J. Zheng, S. Frisco, P. Song, X. Li, The shape-stabilized phase change materials composed of polyethylene glycol and various mesoporous matrices (AC, SBA-15 and MCM-41), Sol. Energy Mater. Sol. Cells 95 (2011) 3550-3556, https://doi.org/10.1016/j.solmat.2011.08.020.
[54] C. Wang, L. Feng, W. Li, J. Zheng, W. Tian, X. Li, Shape-stabilized phase change materials based on polyethylene glycol/porous carbon composite: the influence of the pore structure of the carbon materials, Sol. Energy Mater. Sol. Cells 105 (2012) 21-26, https://doi.org/10.1016/j.solmat.2012.05.031.

[55] X. Min, M. Fang, Z. Huang, Y. Liu, Y. Huang, R. Wen, T. Qian, X. Wu, Enhanced thermal properties of novel shape-stabilized PEG composite phase change materials with radial mesoporous silica sphere for thermal energy storage, Sci. Rep. 5 (2015), https://doi.org/10.1038/srep12964.

[56] T. Qian, J. Li, X. Min, Y. Deng, W. Guan, H. Ma, Polyethylene glycol/mesoporous calcium silicate shape-stabilized composite phase change material: preparation, characterization, and adjustable thermal property, Energy. 82 (2015) 333-340, https://doi.org/10.1016/j.energy.2015.01.043.

[57] Y. Deng, M. He, J. Li, Z. Yang, Polyethylene glycol-carbon nanotubes/expanded vermiculite form-stable composite phase change materials: simultaneously enhanced latent heat and heat transfer, Polymers 10 (2018) 889, https://doi. org $/ 10.3390 /$ polym 10080889 .

[58] S.-G. Jeong, J. Jeon, J.-H. Lee, S. Kim, Optimal preparation of PCM/diatomite composites for enhancing thermal properties, Int. J. Heat Mass Transf. 62 (2013) 711-717, https://doi.org/10.1016/j.ijheatmasstransfer.2013.03.043.

[59] A. Karaipekli, A. Sarı, Development and thermal performance of pumice/ organic PCM/gypsum composite plasters for thermal energy storage in buildings, Sol. Energy Mater. Sol. Cells 149 (2016) 19-28, https://doi.org/ 10.1016/j.solmat.2015.12.034.

[60] Y. Kang, S.-G. Jeong, S. Wi, S. Kim, Energy efficient bio-based PCM with silica fume composites to apply in concrete for energy saving in buildings, Sol. Energy Mater. Sol. Cells 143 (2015) 430-434, https://doi.org/10.1016/ j.solmat.2015.07.026.

[61] D. Zhang, M. Chen, Q. Liu, J. Wan, J. Hu, Preparation and thermal properties of molecular-bridged expanded graphite/polyethylene glycol composite phase change materials for building energy conservation, Materials 11 (2018), https://doi.org/10.3390/ma11050818.

[62] T. Xu, Q. Chen, Z. Zhang, X. Gao, G. Huang, Investigation on the properties of a new type of concrete blocks incorporated with PEG/SiO2 composite phase change material, Build. Environ. 104 (2016) 172-177, https://doi.org/10.1016/ j.buildenv.2016.05.003.

[63] E. Onder, N. Sarier, G. Ukuser, M. Ozturk, R. Arat, Ultrasound assisted solvent free intercalation of montmorillonite with PEG1000: a new type of organoclay with improved thermal properties, Thermochim. Acta 566 (2013) 24-35, https://doi.org/10.1016/j.tca.2013.05.021.

[64] S. Cunha, S. Lucas, J. Aguiar, V. Ferreira, L. Braganca, Influence of incorporation phase change materials, PCM, granulates on workability, mechanical strength and aesthetical appearance of lime and gypsum mortars, Archit. Civ. Eng. Environ. 3 (2013) 39-48.

[65] S. Cunha, J.B. Aguiar, V. Ferreira, A. Tadeu, Influence of adding encapsulated phase change materials in aerial lime based mortars, Adv. Mater. Res. 687 (2013) 255-261, https://doi.org/10.4028/www.scientific.net/AMR.687.255. 